\title{
Türkiye’de Zihinsel Dayanıklılık Konusunda Yapılmış Araştırmaların Analizi ve İncelenmesi
}

\author{
Şenol GÜVEN ${ }^{1}$, Atakan YAZICI ${ }^{* 2}$ \\ ${ }^{1}$ T.C. Milli Eğitim Bakanlığı, Cumayanı Ortaokulu. https://orcid.org/0000-0001-6846-2605. \\ ${ }^{2}$ Gazi Üniversitesi, Spor Bilimleri Fakültesi. https://orcid.org/0000-0001-8899-2515.
}

\section{Orijinal Makale}

Gönderi Tarihi: 09.06.2020
DOI: $10.30769 /$ usbd.749719

Online Yayın Tarihi: 30.06.2020

\section{$\ddot{\mathbf{O} z}$}

Bu araştırmanın amacı, Türkiye'de zihinsel dayanıklılık ile ilgili 2014-2019 yılları arasında yapılmış lisansüstü tezleri ve ULAKBİM Ulusal Veri Tabanında indeksli dergilerde yayımlanmış araştırmaları incelemektir. Doküman incelemesi çalışması olan bu araştırmada 35 lisansüstü tez ve ULAKBİM Ulusal Veri Tabanında indeksli dergilerde yayımlanan 17 araştırma incelenmiştir. İncelemeler sonucu toplanan verilerin yüzdeleri ve frekansları hesaplanmıștır. Araştırmadan elde edilen sonuçlara göre; araştırmaların en çok 2019 yılında yapıldığı, "Mental toughness" kavramının Türkçe karşılığı olarak zihinsel dayanıklılık kavramının kullanılması konusunda hemfikir olunduğu görülmüştür. Ayrıca araştırmaların genellikle ilişkisel tarama modelinde gerçekleştiği, örneklem grubu olarak ergenler, üniversite öğrencileri ve yetişkinler üzerinde gerçekleştirildiği ortaya çıkmıştır.

Anahtar kelimeler: Spor psikolojisi, zihinsel dayanıklılık, doküman analizi.

\section{Analysis of the Studies in the Field of Mental Toughness Published in Turkey}

\begin{abstract}
The aim of this study is to investigate the research that explored mental toughness, which was published as theses/dissertations and articles in indexed journals in Ulakbim National Database in Turkey from 2014 to 2019. In this document review study, 35 postgraduate theses and 17 articles published in indexed journals in the ULAKBIM National Database were examined. The percentages and frequencies of the data collected as a result of the examinations were calculated. The results of this study showed that the majority of the research on mental toughness that was conducted in 2019 agreed on the use of "zihinsel dayanıklıl1k" as a Turkish equivalent of the concept of "mental toughness". The results also showed that relational screening model was a prevalent research method with sample groups of adolescents, college students and adults.
\end{abstract}

Keywords: Sport psychology, mental toughness, document analysis.

\footnotetext{
*Sorumlu Yazar: Atakan Yazıc1, E-posta: atakanyazici1989@gmail.com
} 


\section{GíRIŞ}

Spor bilimleri alanındaki araştırmacı ve uygulayıcılar için, sportif performansı iyileştirebilecek çeşitli yöntemleri keşfetmek ve uygulamak önem arz etmektedir. Bununla birlikte, egzersiz ve spor psikolojisi alanındaki araştırmacılar birçok farklı duygu durumu ile baş edebilmenin yüksek performans hedefine ulaşabilmedeki basamaklardan biri olduğunu belirtmişlerdir. Günümüzde egzersiz ve spor psikolojisi ile ilgili kavramların sportif performans için önem kazanmaya başlaması ve sadece sahada yapılan fiziksel antrenmanın tek başına zirve performans için yeterli olmadığının dikkate alınması gibi bazı sebeplerden dolayı performans ile ilgili bazı psikolojik kavramların daha da popüler hale geldiği görülmektedir. Bu kavramlardan birinin de zihinsel dayanıklılık olarak karşımıza çıktığı söylenebilir.

Zihinsel dayanıklılık, bireyin zorluklarla başa çıkabilme, baskı altında mücadeleye devam etme ve performansını sürdürebilmesini temsil eden çok boyutlu psikolojik bir faktör olarak incelenmiştir. Bu doğrultuda sporcunun sahip olduğu yüksek zihinsel dayanıklılık becerisi, performansta yarattığı farklılıklardan dolayı başarılı sporcuların ortak özelliklerinden biri olarak değerlendirilebilir. Nitekim Cox (2011) elit sporcularda görülen psikolojik özelliklerden birinin zihinsel dayanıklılık olduğunu belirtmiştir. Bu kavram başarılı sporcu olabilmek için önemli görülen yüksek içsel motivasyon, adanmışlık, mücadeleci olma, problem çözme becerisi gibi çeşitli psikolojik becerileri de kapsayan bir terimdir (Clough vd., 2002; Crust ve Clough, 2011; Gucciardi vd., 2015). Ayrıca Connaughton vd., (2008) iş birliği doğrultusunda zihinsel dayanıklılık kavramının (sporcu, antrenör ve spor psikologları) geliştirilebilen ve sürdürülebilen kapsamlı bir süreç olduğunu belirtmiştir.

Loehr' in 1986 yılında zihinsel dayanıklılık ile ilgili yaptığı araştırmalarla birlikte, Gould vd., (1987) da sporda zihinsel dayanıklılığın zirve performansa ulaşabilmedeki en önemli psikolojik olgulardan biri olduğunu belirtmişlerdir. $\mathrm{Bu}$ kavrama yönelik alanyazın incelendiğinde açık bir ifadeye sahip olmamasının yanı sıra net bir karşılığının bulunmadığı görülmektedir (Jones, 2002). Bu yüzden zihinsel dayanıklılık özellikle uygulama ve araştırma açısından egzersiz ve spor psikolojisi alanında son 20 yıldır gündemdedir (Gucciardi, 2017). $\mathrm{Bu}$ dönem incelendiğinde yalnızca birkaç hakemli akademik çalışma rapor edilmiştir. Gucciardi ve Gordon'un (2008) aktardığına göre bu çalışmalar; Bull vd., (2005); Fourie ve Potgieter, (2001); Jones vd., (2002); Thelwell vd., (2005) tarafından yapılmıştır. Jones vd., (2002), Kelly tarafindan 1955 yılında geliştirilen "Kişisel Yapı Teorisini” temel alarak performans sporcularında zihinsel dayanıklılı̆̆ araştıran bir program başlatmışlardır. Özellikle 2000'li yıllarda uluslararası alanyazında bu konuyu daha iyi anlayabilmek için nicel ve nitel çalışmaların bir arada yapıldığı karma modellerden sonra deneysel çalışmalar sporcular üzerinde uygulanmış ve çeşitli ölçüm araçları ortaya konmuştur (Sheard, 2013).

İlk olarak Loehr (1986) tarafından kullanılan zihinsel dayanıklılık ölçüm aracı olan "Psikolojik Performans Envanteri, PPE (Psychological Performance Inventory, PPI)" yedili likert yapıda 42 maddeden oluşmaktadır. Ancak çeşitli araştırmacılar bu envanteri tekrardan psikometrik olarak incelemiş̧ler ve yetersiz olduğunu belirtmişler (Golby vd., 2007). Golby vd., (2007), Loehr (1986) tarafından geliştirilen envanteri daha fazla katılımcı üzerinde psikometrik özellikleri açısından test ederek Alternatif Psikolojik Performans EnvanteriniAPPE (The Alternative Psychological Performance Inventory,PPI-A) geliştirmişlerdir. Çeşitli 
araştırmacılar tarafindan araştırmalarda kullanılan envanter (Sheard ve., 2009), başka araştırmacılar tarafindan da psikometrik olarak yeterli görülmemiş ve eleştirilmiştir (Gucciardi ve Gordon, 2011). Ayrıca zihinsel dayanıklılığın çok boyutlu altyapısını ölçmek açısından yeterli olmadığı üzerine şüpheler ortaya çıkmıştır. Bunun üzerine Clough vd., (2002) zihinsel dayanıklılık kavramının 4C (zorluk/challence - kararlılık / commitment güven / confidence - kontrol / kontrol) bileşenlerine dayanan 48 madde, 5'li likert yapıda Zihinsel Dayanıklılık Ölçeği 48 - ZDÖ48 (Mental Toughness Questionnaire 48- MTQ48) adı verdikleri envanteri geliştirmişlerdir. Ölçek Uluslararası literatürde dikkat çekmiş ve bir çok çalışmada kullanılmıştır (Beckford vd., 2016; Clough vd., 2002; Crust, vd., 2014; Walker vd., 2011). Ancak Gucciardi vd., (2012) araştırmalarında daha geniş sporcu ve farklı alanlardan 20-65 yaş aralığındaki katılımcılar üzerinde ZDÖ48' in faktöriyel geçerliliğini incelemişlerdir. Ölçeğin iki bağımsız örneklemde 4C modelini desteklememişlerdir. Ayrıca araştırma bulguları ölçüm aracının psikometrik ve kavramsal uyum açısından şüphelere neden olduğunu raporlamıştır. Bu doğrultuda psikometrik açıdan şüphe uyandıran bir aracın daha önceden yapılmış çalışmalar açısından tartı̧ılmaya açık olabileceği düşünülebilir. Sheard, Golby ve Van Wersch (2009) tarafından Sporda Zihinsel Dayanıklılık Ölçeği - SZDÖ (Sports Mental Toughness Questionnaire - SMTQ) 3C (confidence/güven - control/kontrol - constancy/ devamlılık) modeli temel alınarak geliştirilmiştir. Bunların dışında, Madrigal vd., (2013) Zihinsel Dayanıkl1lık Ölçeğini-ZDÖ (Mental Toughness Scale-MTS) geliştirmişlerdir. Ölçek 11 madde ve tek boyuttan oluşmaktadır. Genel zihinsel dayanıklılık puanını ölçen ve alt boyutları bulunmayan ZDÖ, zihinsel dayanıklılığın çok boyutlu olan kavramsal yapısının dışında tek boyutlu bir yaklaşım izlemektedir. Ayrıca branşlara yönelik daha özel zihinsel dayanıklılık ölçüm araçları da bu kavramın anlaşılabilmesi için geliştirilmiştir. Bunlar kriket (Gucciardi ve Gordon, 2009), Avustralya'da futbol (Gucciardi vd., 2009), Güney Afrika'da tenis (Cowden, 2018) için yapılmıştır. Nitekim bu çalışmaların diğer özelliği bir kültür üzerinde geliştirilmiş olmasının yanı sıra bir branşa özgü zihinsel dayanıklılık ölçümü için yapılmış olmasıdır. Ülkemizde ise Altıntaş (2015), sporcular üzerinde yaptığ 1 çalışma ile Sheard vd., (2009) tarafından geliştirilen SZDÖ'yi Türkçe' ye uyarlamıştır. Erdoğan ise (2016), Madrigal vd., (2013) ZDÖ çalışmasını Türkçe’ye uyarlamıştır. Ayrıca Miçooğulları (2017)'da, SZDÖ'yi psikometrik açıdan tekrar incelemiş ve Türkçe uyarlama çalışmasını yapmıştır.

Zihinsel dayanıklılığın sportif performans açısından öneminin anlaşılmaya başlanmasıyla birlikte araştırmacılar için zihinsel dayanıklılığ geliştirmek daha da önem kazanmıştır. Araştırmacılar tarafindan bu kavram üst düzey sporcuların sahip olması gereken psikolojik becerilerden biri olarak kabul görmektedir. $\mathrm{Bu}$ doğrultuda araştırmacılar zihinsel dayanıklılığın geliştirilmesinde etkili olan bazı faktörleri de incelemişlerdir. Deneysel ve meta-analiz çalışmalar yardımıyla halen dikkat çeken bir performans özelliği olarak görülen zihinsel dayanıklılığın (Stamatis vd., 2020), uzun dönemli planlama, psikolojik beceri antrenmanları, antrenörün sorumlulukları, mücadeleci ortam, zorluk derecesi yüksek tecrübeler ve kültürlerarası farklar ile birlikte gelişebileceği belirtmiş̧ir (Sheard, 2013).

Zihinsel dayanıklılık kavramı spor psikolojisi literatürü açısından kabul görmesine karşın halen anlaşılabilir bir noktaya varamamıştır. Jones vd., (2002) göre, araştırmacılar spor psikolojisinde kullanılan bu kavramın yeteri kadar anlaşılmadığını belirtmişlerdir. Geçen süre 
içerisinde Uluslararası alanyazın incelendiğinde birçok farklı değişken açısından zihinsel dayanıkl1lığın incelenmesine rağmen yeterli görülmemektedir. Bu araştırmada, zihinsel dayanıklılık kavramı ile ilgili Türkiye'de yapılmış lisansüstü tezlerin ve ULAKBİM Ulusal Veri Tabanında indeksli dergilerde yayımlanmış araştırmaların analizinin yapılması ve mevcut güncel durumun ortaya konması amaçlanmıştır. Bu amaç doğrultusunda aşağıdaki sorulara cevap aranmıştır:

1. İncelenen lisansüstü tezlerin ve araştırmaların yıllara göre dağı̆ımı nasıldır?

2. İncelenen lisansüstü tezlerde ve araştırmalarda "mental toughness" kavramının Türkçe karşılığı olarak hangi kavramlar kullanılmıştır?

3. İncelenen lisansüstü tezlerde ve araştırmalarda hangi araştırma modelleri kullanılmıştır?

4. İncelenen lisansüstü tezler ve araştırmalar hangi gruplar üzerinde yürütülmüşsür?

5. İncelenen lisansüstü tezlerde ve araştırmalarda zihinsel dayanıklılık ile hangi değişkenler ele alınmıştır?

\section{YÖNTEM}

\section{Araştırma Modeli}

$\mathrm{Bu}$ araştırma, Türkiye'de lisansüstü tezlerde ve ULAKBİM Ulusal Veri Tabanında indeksli dergilerde yayımlanmış araştırmalarda yer alan zihinsel dayanıklılık ile ilgili çalışmaların analizlerinin yapıldığı ve güncel durumun detaylı şekilde yorumlandığı, doküman incelemesine dayanan nitel bir araştırmadır. Doküman incelemesi, araştırılması amaçlanan olgu ya da olgular hakkında bilgi içeren yazılı materyallerin analizini kapsamaktadır (Yıldırım ve Şimşek, 2000). Tüm bu analiz ve yorumlamaların sonucunda, bu analiz ve yorumlara dayanarak konu ile ilgili öneriler getirilmiş ve araştırmacıların dikkatine sunulmuştur.

\section{Çalışma Grubu}

Araştırmanın evrenini zihinsel dayanıklılık ile ilgili Türkiye'de yapılan lisansüstü tezler ve ULAKBIM Ulusal Veri Tabanında indeksli dergilerde yayımlanan araştırmalar oluşturmaktadır. Araştırmanın çalışma evreninde belirtilen tüm lisansüstü tezlere ve araştırmalara ulaşmak hedeflenmiş ve bu nedenle örnekleme yoluna gidilmemiştir. Bu durumda araştırmanın çalışma evrenini 2014-2019 yılları arasında YÖK veri tabanında yer alan 35 lisansüstü tez ve ULAKBİM Ulusal Veri Tabanında indeksli dergilerde yayımlanan 17 araştırma oluşturmaktadır.

\section{Veri toplama ve analiz}

$\mathrm{Bu}$ araştırmada veri toplama yöntemi olarak doküman analizi kullanılmıştır. Araştırma konusu ile ilgili çalı̧̧malara ulaşmak için veri tabanlarında "zihinsel dayanıklılık" ve "mental toughness" anahtar sözcükleri kullanılmıştır. Doküman analizinin birinci aşaması olan dokümanlara ulaşmak için,Yükseköğretim Kurulu Başkanlığı (YÖK) Ulusal Tez Merkezi web sitesinden (https://tez.yok.gov.tr/UlusalTezMerkezi/giris.jsp) yüksek lisans ve doktora tezleri, araştırmalar için ise ULAKBİM Ulusal Veri Tabanında indekslenen dergilerin web 
sayfasından pdf formatında bilgisayar ortamına kodlanarak aktarılmıştır. Diğer aşamada ise bilgisayar ortamına aktarılan tezlerin ve araştırmaların analizleri, araştırmacı tarafından hazırlanan değerlendirme ölçütleri dikkate alınarak içerik analizi türlerinden frekans analizi ile yapılmıştır.

\section{BULGULAR}

Araştırma bulguları araştırmanın alt amaçlarının sıralaması ile birlikte aşağıda verilmiştir. Türkiye'de zihinsel dayanıklılık ile ilgili yapılan lisansüstü tezlerin ve araştırmaların yıllara göre dağılımı Tablo 1'de verilmiştir.

Tablo 1. İncelenen lisansüstü tezlerin ve araştırmaların yıllara göre dağılımı

\begin{tabular}{lccccc}
\hline YÖK Veri Tabanı & & & \multicolumn{3}{c}{ ULAKBİM Ulusal Veri Tabanı } \\
\hline Yll & Yüksek LisansTezi & Doktora Tezi & f & Araştırma & f \\
\hline 2014 & 1 & - & 1 & - & - \\
2015 & - & 1 & 1 & - & - \\
2016 & 1 & - & 1 & 2 & 2 \\
2017 & 4 & 1 & 5 & 1 & 1 \\
2018 & 5 & - & 5 & 6 & 6 \\
2019 & 21 & 1 & 22 & 8 & 8 \\
Toplam & 32 & 3 & 35 & 17 & 17 \\
\hline
\end{tabular}

Tablo 1'e göre Türkiye'de zihinsel dayanıklılık ile ilgili 35 lisansüstü tez ve 17 araştırma yapıldığı, bu çalışmaların en çok 2019 yılında gerçekleştiği görülmektedir. Ayrıca yapılan tezlerin lisansüstü düzeylere göre dağılımı incelendiğinde yüksek lisans düzeyinde yapılan tezlerin fazlalığı dikkat çekmektedir.

Türkiye'de zihinsel yeterlilik ile ilgili yapılan lisansüstü tezlerde ve ulusal veri tabanında indekslenen dergilerde yayımlanan araştırmalarda "mental toughness" kavramının Türkçe karşılığı olarak kullanılan kavramlar Tablo 2'de verilmiştir.

Tablo 2. İncelenen lisansüstü tezlerde ve araştırmalarda "mental toughness" kavramının Türkçe karşılığı

\begin{tabular}{lcccc}
\hline \multicolumn{1}{c}{ YÖK Veri Tabanı } & \multicolumn{3}{c}{ ULAKBİM Ulusal Veri Tabanı } \\
\hline $\begin{array}{l}\text { "Mental toughness" Kavramının Türkçe } \\
\text { Karşılığı }\end{array}$ & $\mathbf{f}$ & $\boldsymbol{\%}$ & $\mathbf{f}$ & \% \\
\hline Zihinsel Dayanıklılık & 32 & 91.43 & 15 & 88.23 \\
Mental Dayanıklılık & 2 & 5.71 & 2 & 11.77 \\
Psikolojik Dayanıklılık & 1 & 2.86 & - & - \\
\hline
\end{tabular}

Tablo 2'ye göre “mental toughness” kavramının Türkçe'ye birkaç farklı şekilde çevrildiği ve hemen hemen ortak bir kavram olan "zihinsel dayanıklılık” kavramı üzerinde uzlaşıldığı görülmektedir. "Mental toughness” kavram1, incelenen lisansüstü tezlerin \%91,43’ünde zihinsel dayanıklılık, \%5,71'inde mental dayanıklılık ve \%2,86'sında psikolojik dayanıklılık olarak çevrilmiştir. Ulusal veri tabanında yer alan dergilerde yayımlanan araştırmaların ise $\% 88,23$ 'ünde zihinsel dayanıklılık, \%11,77'sinde ise mental dayanıklılık olarak yer almıştır. $\mathrm{Bu}$ sonuçlardan anlaşılabileceği üzere alanyazında zihinsel dayanıklılık olgusunun benzer bir bakış açısıyla ele alınmış olduğu düşünülebilir.

Türkiye'de zihinsel dayanıklılık ile ilgili yapılan lisansüstü tezlerin ve ulusal veri tabanında indekslenen dergilerde yayımlanan araştırmaların araştırma desenine göre dağılımı Tablo 3'de verilmiştir. 
Güven, Ş., ve Yazıcı, A. (2020). Türkiye'de zihinsel dayanıklılık konusunda yapılmış araştırmaların analizi ve incelenmesi. Ulusal Spor Bilimleri Dergisi, 4(1), 82-93.

Tablo 3. İncelenen lisansüstü tezlerin ve araştırmaların araştırma desenine göre dağılımı

\begin{tabular}{lcccc}
\hline YÖK Veri Tabanı & & & \multicolumn{2}{c}{ ULAKBİM Ulusal Veri Tabanı } \\
\hline Araştırma Deseni & f & \% & f & \% \\
\hline İlişkisel Tarama & 14 & 40 & 7 & 41,17 \\
Betimsel & 9 & 25,75 & 6 & 35,29 \\
Karşıștırmalı & 7 & 20 & 2 & 11,76 \\
Deneysel & 3 & 8,55 & 1 & 5,89 \\
Nitel & 1 & 2,85 & 1 & 5,89 \\
Karma Desen & 1 & 2,85 & - & - \\
\hline
\end{tabular}

Tablo 3 incelendiğinde lisansüstü tezlerin \% 40'ının, ulusal veri tabanında indekslenen dergilerde yayımlanan araştırmaların da \% 41,17'sinin iki ya da daha fazla değişken arasındaki birlikte değişimin varlığını ya da derecesini belirlemeyi amaçlayan ilişkisel tarama deseni ile gerçekleştirildiği görülmüştür. Lisansüstü tezlerin \% 25,75'inin, ulusal veri tabanında indekslenen dergilerde yayımlanan araştırmaların da \% 35,29'unun betimsel desen kullanılarak gerçekleştirildiği bulgusuna rastlanmıştır. Bunların yanı sıra lisansüstü tezlerin 7'si karşılaştırmalı, 3'ü deneysel ve 1 tanesi nitel ve karma desen olarak yapılandırılmıştır. Ulusal veri tabanında indekslenen dergilerde yayımlanan araştırmalar gözden geçirildiğinde ise 2'sinin karşılaştırmalı, 1'inin ise deneysel ve nitel araştırma deseni olarak tasarlandığı görülmektedir.

Türkiye'de zihinsel dayanıklılık ile ilgili yapılan lisansüstü tezlerin ve ulusal veri tabanında indekslenen dergilerde yayımlanan araştırmaların örneklem türüne göre dağılımı Tablo 4'de verilmiştir.

Tablo 4. İncelenen lisansüstü tezlerin ve araştırmaların örneklem türüne göre dağılımı

\begin{tabular}{lcc}
\hline YÖK Veri Tabanı & U & ULAKBİM Ulusal Veri Tabanı \\
\hline Araştırma Deseni & 23 & f \\
\hline Yetişkinler & 13 & 10 \\
Ergenler & 6 & 6 \\
Üniversite Öğrencileri & & 6 \\
\hline
\end{tabular}

Tablo 4'te zihinsel dayanıklılık ile ilgili lisansüstü çalışmalarda ve ulusal veri tabanında indekslenen dergilerde yayımlanan araştırmalarda en çok yetişkin örneklem grubu ile araştırma yapıldığı görülmektedir. Bazı çalışmalarda hem yetişkinler hem de ergenler örneklem grubu olarak seçildiğinden örneklem grubu toplam sayıları yapılan araştırma sayılarından fazladır. Yapılan tüm çalışmalar incelendiğinde çocuk örneklem grupları ile ilgili herhangi bir çalışmaya rastlanmamıştır.

Türkiye'de zihinsel dayanıklılık ile ilgili yapılan lisansüstü tezlerde ve ulusal veri tabanında indekslenen dergilerde yayımlanan araştırmalarda zihinsel dayanıklılık ile ilişkilendirilen değişkenler Tablo 5'te verilmiştir. 
Güven, Ş., ve Yazıcı, A. (2020). Türkiye'de zihinsel dayanıklılık konusunda yapılmış araştırmaların analizi ve incelenmesi. Ulusal Spor Bilimleri Dergisi, 4(1), 82-93.

Tablo 5. İncelenen lisansüstü tezlerde ve araştırmalarda zihinsel dayanıklılık ile ilişkilendirilen değişkenler

\begin{tabular}{|c|c|c|}
\hline & Tabanı & ULAKBİM Ulusal Veri Tabanı \\
\hline Değiskenler & f & $\mathbf{f}$ \\
\hline Demografik Değişkenler & 20 & 9 \\
\hline Duygusal Zekâ & 4 & - \\
\hline Hedef Yönelimi & 2 & - \\
\hline Kendinle Konuşma & 2 & 1 \\
\hline Öz yeterlilik & 2 & - \\
\hline Yorgunluk etkisi & 1 & 1 \\
\hline Güdülenme düzeyi & 1 & - \\
\hline Optimal performans duygu durumu & 1 & - \\
\hline Tutkunluk düzeyi & 1 & 1 \\
\hline Performans beklentisi & 1 & - \\
\hline Benlik saygisı & 1 & - \\
\hline Kișilik & 1 & 1 \\
\hline Pozitif alg1 & 1 & 1 \\
\hline Futbolda mevki & 1 & - \\
\hline Sosyal destek rolü & 1 & - \\
\hline Bilinç farkındalık düzeyi & 1 & - \\
\hline Ailenin spora dahiliyeti & 1 & - \\
\hline Aile mükemmeliyetçilik algısı & 1 & - \\
\hline Mücadele ve tehdit algısı & 1 & - \\
\hline Duygu durum & 1 & - \\
\hline Psikolojik performans danışmanlığ & 1 & - \\
\hline Sportif kendine güven & 2 & - \\
\hline E-spor & 1 & - \\
\hline Bilişsel esneklik & 1 & 1 \\
\hline Başarı hedefi & 1 & - \\
\hline İmgeleme & 1 & - \\
\hline İçsel konuşma & 1 & - \\
\hline Stresle başa çıkma & 1 & - \\
\hline Bağlanma stilleri & 1 & - \\
\hline Bilişsel duygu düzenleme & 1 & - \\
\hline Branşa özgü teknik parametreler & 1 & - \\
\hline Branşa özgü performans & 1 & - \\
\hline Yaşam sağll $\breve{g}_{1}$ & 1 & - \\
\hline Olumlu düşünme becerisi & 1 & - \\
\hline Performans duygu durumu & 1 & - \\
\hline Yalnızlık düzeyi & - & 1 \\
\hline Cesaret düzeyi & - & 1 \\
\hline Spor yapma y1lı & - & 2 \\
\hline Antrenör ile çalışma süresi & - & 1 \\
\hline Sakatlık durumu & - & 1 \\
\hline Millilik & - & 1 \\
\hline Ceza alma durumu & - & 1 \\
\hline Tükenmişlik & - & 1 \\
\hline Egzersiz bağımlılı̆g 1 & - & 2 \\
\hline
\end{tabular}

Tablo 5 incelendiğinde zihinsel dayanıklılık ile en çok ilişkilendirilen değişkenlerin lisansüstü tezlerde demografik değişkenler, duygusal zekâ, hedef yönelimi, kendinle konuşma ve öz yeterlilik olduğu görülmüştür. Ulusal veri tabanında indekslenen dergilerde yayımlanan 
araştırmalarda ise en çok demografik değişkenlerin, egzersiz bağımlılığının ve spor yapma yılının incelendiği bulgusuna rastlanmıştır.

\section{TARTIŞMA VE SONUÇ}

Bu araştırmada Türkiye'de zihinsel dayanıklılık ile ilgili yapılan 35 lisansüstü tez ve 17 araştırma karşılaştırmalı bir şekilde incelenmiş ve tüm bu çalışmalardaki genel eğilim ve farkl111klar ortaya konulmuştur.

Araştırma sonucunda zihinsel dayanıklılık ile ilgili lisansüstü tezlerin ve ulusal veri tabanında indeksli dergilerde yayımlanan araştırmaların ilk olarak 2014 yılında yapıldığı ve her geçen yıl tez ve araştırma sayısının arttığı sonucuna ulaşılmıştır (Tablo 1). Bununla birlikte 2019 yılında lisansüstü tez ve araştırma sayısının en fazla olduğu yıl olmuştur. Bu durum son yıllarda zihinsel dayanıklılık kavramının özellikle spor bilimleri alanındaki araştırmacılar tarafından önemsendiğini göstermesi açısından önemlidir. Özellikle spor ortamındaki yüksek performans beklentisi, branşa özgü araç gereç ve malzeme temininin karşılanmakta yaşanan zorluklardan kaynaklanan güdülenme eksikliği ya da bozulması, sıkça yaşanan eleştirilme korkusu gibi durumlar düşünüldüğünde, zihinsel dayanıklılık kavramının daha iyi anlaşılması performans kaybını önleyici ve koruyucu olarak yapılabilecek çalışmalar açısından önemli görülebilir.

"Mental toughness" kavramının alanyazındaki Türkçe karşılıkları incelendiğinde zihinsel dayanıklılık, mental dayanıklılık ve psikolojik dayanıkl11ık kavramları kullanılmakla birlikte en çok zihinsel dayanıklılık kavramının kullanıldığı (Tablo 2) görülmüştür. Bu sonuç dikkate alındığında "mental toughness" kavramının Türkçe' ye karşılığının alanyazında fikir ayrılığı yaşanmadan kullanıldığ 1 söylenebilir.

Tablo 3 incelendiğinde gerek lisansüstü tezlerin gerekse ulusal veri tabanında indeksli dergilerde yayımlanan araştırmaların büyük bir çoğunluğunun zihinsel dayanıklılık ve çeşitli değişkenler arasındaki ilişkileri belirlemeyi amaçlayan ilişkisel tarama modelinde gerçekleştiği ortaya çıkmıştır. Araştırmadan elde edilen diğer bir sonuç da zihinsel dayanıklılık ile ilişkisi incelenen değişkenlerin (Tablo 5) en çok demografik değişkenler, duygusal zekâ, kişilik, spor yapma yılı, hedef yönelimi, kendinle konuşma, öz yeterlilik, sportif kendine güven gibi psikolojik faktörler olduğu görülmüştür. Elde edilen bu iki bulgu, Türkiye'de zihinsel dayanıklılık kavramının spor ortamında performansa etki edebileceği düşünülen psikolojik bazı olgular çerçevesinde incelendiğini göstermektedir. Yurt dış1 alanyazında zihinsel dayanıklılık ile ilgili mevcut durumu ortaya koyan araştırmalar incelendiğinde, alanyazın açısından yeterince deneysel araştırma yapılmadığı görülmektedir. Uluslararası alanyazın incelendiğinde Clough vd., (2002) tarafından geliştirilen 4C modeli; Sheard (2013) tarafından ortaya konulan 3C modeli ve Fletcher (2005) tarafından geliştirilen FACED modeli gibi modeller görülmektedir. Bu modeller kişilik veya pozitif psikoloji temel alınarak geliştirilip spora uyarlanmış çalışmalardır (Yazıcı, 2019). Ancak alanyazında halen geliştirilmiş kuram çalışmaları konuyla ilgili araştırmaların eksikliğinden dolayı görülmemektedir. Bunun nedenlerinden birinin kültürlerarası ve ulusal araştırma evrenlerindeki çalışmaların yetersizliği olduğu söylenebilir. 
Yukarıdaki bilgilere ek olarak sporcuların gerçek performans ortamında yapılan deneysel ve yarı deneysel araştırmaların sayısının oldukça az olduğu görülmektedir. Yazıcı vd., (2018) bireysel performans antrenman uygulamalarını yarı deneysel bir çalışmayla incelemiş ve bu çalışmaların zihinsel dayanıklılığa pozitif etkisi olduğunu raporlamıştır. Gelişen bireysel becerilerin, özgüvene olan etkisinin performans açısından ilişkisi olduğu araştırma sonucundaki bulgular ışığında söylenebilir. Ayrıca yapılan yalnızca tek kültürlerarası çalışma sonucunda, profesyonel basketbolcuların (Türk-Amerikan) arasında Amerikalı sporcuların zihinsel dayanıklılığın devamlılık ve kontrol boyutlarında Türk sporculara göre daha yüksek ortalamalara sahip olduğu bulgusuna rastlanmaktadır (Yazıcı ve Güçlü, 2019). Farklı yaklaşımlardan ortaya çıkacak araştırma desenleriyle sporcuların zihinsel dayanıklılık becerilerinin gelişimi üzerine ve performanslarının arttırılmasına yönelik çalışmalar alanyazına katkı sağlayacaktır.

Kavramsal olarak zihinsel dayanıklılık uzun vadeli planlar ve uygulamalı yaklaşımların kullanılmasıyla geliştirilebilir bir özelliktir. Bu yapının temelinde yer alan pozitif psikoloji (Lin vd., 2017) yaklaşımı antrenör, sporcu ve aile üçgenindeki ilişkilerin düzenlenmesi açısından da önem arz etmektedir. Sporcunun alt yapı yıllarından itibaren geliştireceği zihinsel beceriler, profesyonel spor yaşantısına geçiş ve başarı için, kendisine olumlu katkılar sağlayabilir.

Sporcularda, sürdürülebilir performans için geliştirilmesi gereken psikolojik becerilerden biri olan zihinsel dayanıklılığın daha iyi anlaşılabilmesi için hem teorik hem de uygulamalı araştırmalar alanyazına, araştırmacılara ve antrenörlere 1şık tutabilir. Bu alanda çalışan kişilerin sahada yapacakları uygulamalı çalışmaların mevcut bilgi birikimine önemli katkılar sağlayabileceği düşünüldüğünde zihinsel dayanıklılık ile ilgili özellikle deneysel çalışmalara olan ihtiyaç daha önemli hale gelmektedir.

Yayın Etiği: Bu çalışmanın hazırlanma ve yazım sürecinde "Yükseköğretim Kurumları Bilimsel Araştırma ve Yayın Etiği Yönergesi" kapsamında bilimse, etik ve alıntı kurallarına uyulmuş olup; toplanan veriler üzerinde herhangi bir tahrifat yapılmamış ve bu çalışma herhangi başka bir akademik yayın ortamına değerlendirme için gönderilmemiştir. 
Güven, Ş., ve Yazıcı, A. (2020). Türkiye'de zihinsel dayanıklılık konusunda yapılmış araştırmaların analizi ve incelenmesi. Ulusal Spor Bilimleri Dergisi, 4(1), 82-93.

\section{KAYNAKLAR}

Altıntaş, A. (2015). Sporcuların zihinsel dayanıklllıklarının belirlenmesinde optimal performans duygu durumu, güdülenme düzeyi ve hedef yöneliminin rolü. Ankara Üniversitesi Sağl1k Bilimleri Enstitüsü, Ankara.

Beckford, T. S., Poudevigne, M., Irving, R. R., \& Golden, K. D. (2016). Mental toughness and coping skills in male sprinters. Journal of Human Sport and Exercise, 11(3), 338-347. https//doi.org/10.14198/jhse.2016.113.01.

Bull, S., Shambrook, C., James, W., \& Brooks, J. (2005). Towards and understanding of mental toughness in elite English cricketers. Journal of Applied Sport Psychology, 17, 209-227. https://doi.org/10.1080/10413200591010085.

Clough, P., Earle, K., \& Sewell, D. (2002). Mental toughness: The concept and its 935 measurement. In I. Cockerill (Ed.), Solutions in sport psychology (pp. 32-45). London: 936 Thomson.

Connaughton, D., Wadey, R., Hanton, S., \& Jones, G. (2008). The development and maintenance of mental toughness: Perceptions of elite performers. Journal of sports sciences, 26(1), 83-95. https://doi.org/10.1080/02640410701310958.

Cowden, R. G. (2018). Mental Toughness Inventory: Factorial validity and ethnic group measurement equivalence in competitive tennis. Current Psychology, 39, 736-741. https://doi.org/10.1007/s12144018-9798-6.

Cox, R. (2011). Sport Psychology. Concepts and Applications (7th ed.). New York: McGraw-Hill Education.P:564. ISBN:9780078022470.

Crust, L., \& Clough, P. (2011). Developing mental toughness: From research to practice. Journal of Sport Psychology in Action, 2(1),21-32. https://doi.org/ 10.1080/21520704.2011.563436.

Crust, L., Earle, K., Perry, J., Earle, F., Clough, A., \& Clough, P. J. (2014). Mental toughness in higher education: Relationships with achievement and progression in first-year university sports students. Personality And Individual Differences, 69, 87-91. https://doi.org/ 10.1016/j.paid.2014.05.016.

Erdoğan, N. (2016). Zihinsel Dayanıklılık Ölçeği (ZDÖ): Türkçe'ye uyarlama, geçerlik ve güvenirlik çalışması. International Journal of Sport Culture and Science, 4 (Special Issue 2), 652-664. https://doi.org/10.14486/IntJSCS588.

Fletcher, D. (2005). "Mental toughness" and human performance: Definitional, conceptual and theoretical issues. Journal of Sport Sciences, 23, 1246-1247. https://doi.org/10.1080/02640410500209153.

Fourie, S., \& Potgieter, J. (2001). The nature of mental toughness in sport. South African Journal for Research in Sport, Physical Education and Recreation, 23, 63-72. https://doi.org/10.4314/sajrs.v23i2.25860.

Golby, J., Sheard, M., \& Van Wersch, A. (2007). Evaluating the factor structure of the psychological performance inventory. Perceptual and Motor Skills, 105(1), 309-325. https://doi.org/10.2466/pms.105.1.309-325.

Gould, D., Hodge, K., Peterson, K., \& Petlichkoff, L. (1987). Psychological foundations of coaching: Similarities and differences among intercollegiate wrestling coaches. The Sport Psychologist, 1, $293-$ 308. https://doi.org/10.1123/tsp.1.4.293.

Gucciardi, D. F. (2017). Mental toughness: progress and prospects. Current Opinion in Psychology,16, 17-23. https://doi.org/https://doi.org/10.1016/j.copsyc.2017.03.010.

Gucciardi, D. F., \& Gordon, S. (2008). Personal construct psychology and the research interview: the example of mental toughness in sport. Personal Construct Theory and Practice, 5, 119-130. 
Güven, Ş., ve Yazıcı, A. (2020). Türkiye'de zihinsel dayanıklılık konusunda yapılmış araştırmaların analizi ve incelenmesi. Ulusal Spor Bilimleri Dergisi, 4(1), 82-93.

Gucciardi, D. F., \& Gordon, S. (2009). Development and preliminary validation of the Cricket Mental Toughness Inventory (CMTI). Journal of Sports Sciences, 27(12), 1293-1310. https://doi.org/10.1080/02640410903242306.

Gucciardi, D. F., \& Gordon, S. (Eds.). (2011). Mental toughness in sport: Developments in theory and research (Vol. 1). London: Routledge.

Gucciardi, D. F., Gordon, S., \& Dimmock, J. A. (2009). Development and preliminary validation of a mental toughness inventory for Australian football. Psychology of Sport and Exercise, 10(1), 201-209. https://doi.org/10.1016/j.psychsport.2008.07.011.

Gucciardi, D. F., Hanton, S., \& Mallett, C. J. (2012). Progressing measurement in mental toughness: A case example of the Mental Toughness Questionnaire 48. Sport, Exercise, and Performance Psychology, 1(3), 194-214. https://doi.org/10.1037/a0027190.

Gucciardi, D. F., Hanton, S., Gordon, S., Mallett, C., \& Temby, P. (2015). The Concept of Mental Toughness: Tests of Dimensionality, Nomological Network, and Traitness. Journal of Personality, 83(1), 26-44. https://doi.org/10.1111/jopy.12079.

Jones, G., Hanton, S., \& Connaughton, D. (2002). What is this thing called mental toughness? An investigation with elite performers. Journal of Applied Sport Psychology, 14, 211 - 224. https://doi.org/10.1080/10413200290103509.

Jones, J. (2002). What Is This Thing Called Mental Toughness? An Investigation of Elite Sport Performers. Journal of Applied Sport Psychology, 14(3), 205-218. https://doi.org/10.1080/10413200290103509.

Kelly, G. A. (1955). The psychology of personal constructs. New York: Norton.

Lin, Y., Mutz, J., Clough, P., \& Papageorgiou, K. (2017). Mental Toughness and Individual Differences in Learning, Educational and Work Performance, Psychological Well-being, and Personality: A $\begin{array}{lllll}\text { Systematic } & \text { Review. } & \text { Frontier } & \text { Psychology } & \text { 8(1345), }\end{array}$ https://doi.org/https://doi.org/10.3389/fpsyg.2017.01345.

Loehr, J. E. (1986). Mental toughness training for sports: Achieving athletic excellence. Lexington: MA:Stephan Greene Press.

Madrigal, L., Hamill, S., \& Gill, D. L. (2013). Mind over matter: The development of the Mental Toughness Scale (MTS). The Sport Psychologist, 27(1), 62-77. https://doi.org/10.1123/tsp.27.1.62.

Miçooğullari, B. O. (2017). The Sports Mental Toughness Questionnaire (SMTQ): A Psychometric evaluation of the Turkish version. Studia sportiva, 11(2), 90-98.https://doi.org/10.5817/StS2017-2-9.

Sheard, M. (2009). A cross-national analysis of mental toughness and hardiness in elite university rugby league teams. Perceptual and motor skills, 109(1), 213-223. https://doi.org/10.2466/PMS.109.1.213-223.

Sheard, M. (2013). Mental toughness: The mindset behind sporting achievement (2nd ed.). London: Routledge/Taylor \& Francis Group.

Sheard, M., Golby, J., \& Van Wersch, A. (2009). Progress toward construct validation of the Sports Mental Toughness Questionnaire (SMTQ). European Journal of Psychological Assessment, 25, 184-191. https://doi.org/10.1027/1015-5759.25.3.186.

Stamatis, A., Grandjean, P., \& Morgan, G., Padgett, R.N., Cowden, R., \& Koutakis, P. (2020). Developing and training mental toughness in sport: a systematic review and metaanalysis of observational studies and pre-test and posttest experiments. BMJ Open Sport \& Exercise Medicine, 6, 1-9. e000747. doi:10.1136/bmjsem-2020-000747.

Thelwell, R., Weston, N., \& Greenlees, I. (2005). Defining and understanding mental toughness within soccer. Journal of Applied Sport Psychology, 17, 326-332. https://doi.org/10.1080/10413200500313636. 
Walker, T. B., Lennemann, L. M., McGregor, J. N., Mauzy, C., \& Zupan, M. F. (2011). Physiological and psychological characteristics of successful combat controller trainees. Journal of Special Operations Medicine 11(1), 39-47. https://doi.org/10.21236/ada530307.

Yazıcı, A. (2019). Kavramsal bakış açısı ile sporda üstün başarı için zihinsel dayanıklılık. In N. Dal (Ed.), Spor psikolojisinde yeni yaklaşımlar (pp. 75-97). Ankara: Akademisyen Kitabevi. ISBN: 978-605-258687-7.

Yazıcı, A., \& Güçlü, M. (2019). Psikolojik performans farklılıklarl açısından profesyonel basketbol: Profesyonel basketbol oyuncularında zihinsel dayanıklılık ve duygusal zekânın çeşitli değişkenler açısından incelenmesi. LAP LAMBERT Academic Publishing. ISBN: 978-613-9-99198-3

Yazıc1, A., Savaş, S., \& Günay, M. (2018). The Effect of implementation of a 6-week basketball-specific aerobic training on mental toughness and anxiety variables. IV. International Exercise and Sport Psychology Congress 13-15 April, 37. Retrieved from http://esp2018.kongre.marmara.edu.tr/en/.

Yıldırım, A. \& Şimşek, H. (2000). Sosyal bilimlerde nitel araştırma yöntemleri (Gözden geçirilmiş 2. bs.). Ankara: Seçkin Yayıncılık.

Bu eser Creative Commons Atıf-GayriTicari 4.0 Uluslararası Lisansı ile lisanslanmıştır. 